\title{
IMPACT OF WORKING ENVIRONMENT FACTORS ON EMPLOYEES IN SELECTED SMALL ENGINEERING ENTERPRISES
}

\author{
Viera Bestvinová \& Petra Marková*
}
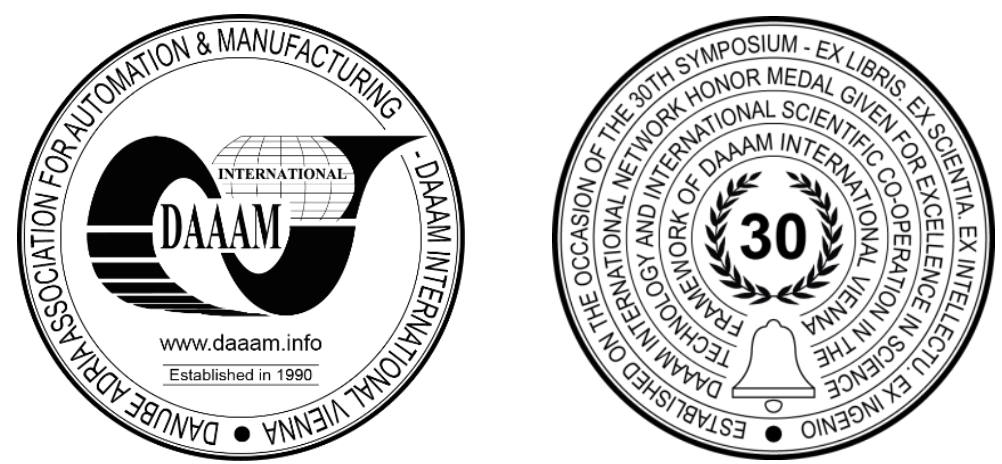

This Publication has to be referred as: Bestvinova, V[iera] \& Markova, P[etra] (2020). Impact of Working Environment Factors on Employees in Selected Small Engineering Enterprises, Proceedings of the 31st DAAAM International Symposium, pp.0111-0117, B. Katalinic (Ed.), Published by DAAAM International, ISBN 978-3-902734-29-7, ISSN 1726-9679, Vienna, Austria

DOI: $10.2507 / 31$ st.daaam.proceedings.015

\begin{abstract}
In the work environment, a person by work performance interacts with the work environment, work equipment, work objects and, last but not least, with a number of risk factors. These result from the nature of the work activity and also from the work environment. The influence of the work environment factors on humans can be added up, multiplied but also reduced or eliminated. We are talking about the combined effects of risk factors. Based on these facts, it is clear that it is necessary to address the impact of work environment factors on employees. The paper deals with the investigation of the impact of working environmental factors on the performance and comfort of employees in selected small engineering companies. For the paper, employees subjective evaluated factors of the working environment that affect the performance of their work. The obtained information is used to develop an idea of the work environment factors affecting employees of the small engineering companies. The aim was to find out whether the factors of the work environment influence the work performance of employees in terms of the quality of work performed. The results of the analysis indicate that the examined factors of the working environment have an impact on employees. It is important to examine their positive or negative impact on the employees' performance. Based on more detailed research of work comfort factors in engineering operations, it will be possible to assign importance to work factors and examine their interactions and to develop a combined procedure for indexing work comfort factors.
\end{abstract}

Keywords: working environment; factors of working environment; working comfort; employees, workplace

\section{Introduction}

Development of production, insufficient use of personal protective equipment, work in stress, prolongation of working-age etc. it can be seen as a negative impact of the working environment on the health of employees in all industries. Especially in engineering plants, there are dangerous factors of the working environment that can damage their health by prolonged and repeated exposure to employees. Therefore, the emphasis is on adopting technical, organizational and other measures to eliminate or reduce to a minimum the impact of hazardous environmental factors on employees. The most important tasks of employers in this area are to create a safe working environment, to ensure workability and working comfort of employees. Remove, respectively reducing the impact of unfavourable factors in the working environment improves the working comfort of employees and also improves employee performance. 
Many studies have recognised the important role played by the organisations management in reducing accidents [4], [5], [6] because of that, accidents have adverse effects in terms of productivity and quality decreasements, deterioration of the organisations public image and internal climate [7]. Thus, many authors have already established numerous factors that have a strong influence on OH\&SMS, including: (1) leadership, (2) employee involvement, (3) work environment, (4) stress management and (5) OHS training [13].

The aim of the paper, which is part of the project VEGA 1/0101/18 - Proposal of the combination and recombination methodology for the work comfort index in mechanical engineering industrial plants, is to find out, based on the survey, whether there is an influence of selected work environment factors in the workplace and work environment factors to employees in small engineering companies.

\subsection{Problems of examination of working environment factors}

Today's global and turbulent environment is characterized by rapidly changing conditions. Businesses are thinking deeply about how to innovate their production processes, looking for more efficiency and quality, but they often lack specific projects and strategies to put these requirements into practice [10]. Working conditions are at the core of paid work and employment relationships. Generally speaking, working conditions cover a broad range of topics and issues, from working time (hours of work, rest periods, and work schedules) to remuneration, as well as the physical conditions and mental demands that exist in the workplace [15].

The working environment is a summary of all material conditions of work (machinery and equipment, handling equipment, personal protective equipment, raw materials, material and other work equipment), which together with other conditions (technology, work organization, social conditions of work) create factors of the working environment physical, chemical, biological, socio-psychological and others that affect the employee during the work process [8]. The most frequently evaluated factors in engineering include noise, vibration, lighting, temperature, respectively cold in the workplace, dustiness, air flow, etc. Each of them may present a health risk in certain circumstances. Prolonged exposure of workers to excessive noise can cause hearing loss or impairment of hearing or hearing loss from noise. Working in a forced position with frequent repetition of individual actions with force can lead to musculoskeletal disorders. The vibrations can cause nausea and discomfort. What this tells us is that working in non-adequate environment effects health condition of the employees on a high level [1]. The assessment of the level of exposure, especially of physical factors in the work process and their comparison with the permissible values specified in the decrees of the Ministry of Health of the Slovak Republic is not a bottleneck. The problem is a comprehensive assessment of the working environment to assess the interaction of individual factors on employees in working in the working environment.

At present, the project is based on many years of experience of employees of the Institute of Industrial Engineering and Management of the Faculty of Materials Science and Technology in Trnava in the field of ergonomics and industrial management. Research results (eg. VEGA project "Transformation of the ergonomic program into a company management structure by integration and use of QMS, EMS, HSMS modules", APVV project "Transformation of Industry in Slovakia by using Participatory Ergonomics", bilateral USA - Slovak project "Transforming Industry in Slovakia Through Participatory Ergonomics") pointed out the need for a comprehensive evaluation of ergonomic indicators in industrial plants. Despite efforts to express the synergic effect of physical and ergonomic factors with using mathematical and statistical methods, there is still no model that would allow their combination and recombination with regard to individual needs of employees, especially in industrial companies [11].

The problems closely related to the evaluation of working comfort in terms of assessing the workload of employees caused by individual factors of the working environment are found in the work of several authors. Benefit in this area was the paper of M. Kapustová [9], which describes the mathematical model of the evaluation of workload of employees, which explains the overall impact of factors of the working environment on the employee and also allows to evaluate the complex burden of a human organism during working hours.

The issue of the working environment is paid not only in the field of theoretical research and the application of its results into business practice, but organizations on a transnational and national level examine in a broad context the impact of working conditions on human. Eurofound foundation is an EU agency dedicated to improving living and working conditions. One of the three research areas of this agency is the European Working Conditions Survey (EWCS). The European Working Conditions Survey is the longest ongoing survey and has become a recognized source of information on working conditions and the quality of work and employment. Established since 1990, it allows monitoring of longterm trends in working conditions in Europe. This survey covers the areas of the physical environment, work intensity, working time schedule, workplace relationships, skills, authority and employment status and working life perspectives [4]. The last, sixth survey of working conditions (2015), which included other European countries in addition to the EU Member States, revealed a diversity of working conditions by country, occupation, gender and age group. The findings of the survey highlight the areas to be pursued at EU and country level to achieve sustainable development of working conditions. Based on respondents' answers, the Slovak Republic achieved an average score in almost all assessment areas, with the highest score in terms of work stability and lowest in terms of the use of personal protective equipment, fastworking and lack of time to work, justice, cooperation and trust. Employee participation in improving work organization and working practices. Slovakia needs competitive companies that create decent working conditions for its employees because the working environment is one of the important factors that influence people in making decisions and staying in it. Also an employee's motivation to work is heavily influenced by his or her environment [3]. 


\section{Materials and methodology of experiment}

The paper presents partial results of the project VEGA 1/0101/18 - Proposal of the combination and recombination methodology for the work comfort index in mechanical engineering industrial plants. To determine the impact of work environment factors on employees with regard to their work comfort, two engineering companies employing less than 50 employees were randomly selected. The annual turnover and balance sheet total amount to EUR 10 million and thus belong to the small business group. We chose these companies for our survey because they are comparable companies in terms of the number of employees, organization of production and equipping of enterprises with means of production. In addition to standard machine tools such as horizontal and coordinate boring machines, conventional lathes, welding machines, various types of grinding machines, etc. companies are equipped with special technological equipment for electro-erosive cutting and sinking and CNC machine tools. In the surveyed enterprises, there is a nesting arrangement of workplaces for the performance of the specialized technological processes. The business activities of the companies are mainly toolmaking, metalworking, locksmithing, production of metal products, and production of simple machines for economic sectors, maintenance and modification of injection moulds for plastic mouldings for the automotive and electrical industries. In companies, we conducted a questionnaire survey to determine the impact of factors of the working environment in terms of work comfort of employees based on the subjective assessment of employees. 62 respondents $(63.07 \%)$ out of 98 participated in the questionnaire survey. The selected sample of respondents is homogeneous in terms of gender, as all employees are men. Respondents were divided into four groups. They differ in the degree of workload, the scope of work and also the type of workplace. Table 1 shows the exact number of representations in each group, the percentage conversion and the professions in the group.

\begin{tabular}{|c|c|c|c|}
\hline Profession & Acronym & Frequency & Percentage \\
\hline Employees on CNC machines & CNC & 18 & $29.28 \%$ \\
\hline Employees on conventional machines & CM & 10 & $17.08 \%$ \\
\hline Manual workers & MW & 20 & $31.70 \%$ \\
\hline Technical and economic staff & TES & 14 & $21.94 \%$ \\
\hline Together & & 62 & $100.00 \%$ \\
\hline
\end{tabular}

Table 1. Division of respondents into professional working groups

The questionnaire included groups of questions about the factors of the work environment influencing the work comfort of employees: basic non-modifiable factors for the description of the selected sample of respondents, job classification, MSD problems, work microenvironment factors and mental stress factors. Due to the fact that these are small companies and the selected sample does not have a sufficient number, it is not possible to make a statistical evaluation based on the results, but it is possible to observe the development of a certain trend. The information obtained is sufficient to confirm that there are factors in the working environment that affect the working comfort of employees. For the interpretation of the purpose of the outputs of the questionnaire survey, we used a cross - sectional descriptive study. We used basic statistical characteristics (mean values, minimum values, lower quartile, median, upper quartile and maximum age, occupational exposure at a given job, body height, body weight, Body mass index and Rohrer index). In addition to the questionnaire method, we used the method of interview and direct observation to assess the impact of modifiable factors of the working environment.

\section{Reached results}

The characteristic of non-modifiable factors with a direct effect on the health and performance of employees, can be seen in Table no.2. The respondents were examined for non-modifiable or personality factors. These are age, work exposure, sex, height, body weight and the resulting BMI and Rohrer index. In terms of gender, the sample was not divided as all respondents are men. Almost all the employees, who involved in the survey are of productive age but are more likely to be older workers, who have been employed in a given job for a long time, are incorporated, and based on an assessment of their responses, it is possible to assess the real impact of the working environment factors affecting them. In the examined sample of employees are represented mostly tall men with higher body weight that was reflected in a higher Body Mass Index value. Defining the examined sample of employees makes it possible to assess the influence of work comfort factors in terms of non-modifiable factors affecting employees. Their impact must be taken into account when implementing corrective measures to reduce or eliminate negative factors in the work environment.

\begin{tabular}{|c|c|c|c|c|c|c|c|c|c|}
\hline \multirow[t]{2}{*}{ Parameter } & \multirow{2}{*}{$\begin{array}{l}\text { Work group } \\
\text { acronym }\end{array}$} & \multicolumn{8}{|c|}{ Statistical characteristics } \\
\hline & & $\mathrm{n}$ & $\overline{\mathbf{x}}$ & S.D & Min. & $25 \%$ il & Median & $75 \%$ il & Max \\
\hline \multirow{3}{*}{$\frac{8}{4}$} & $\mathrm{CNC}$ & 18 & 36.08 & 10.69 & 21.00 & 29.00 & 34.50 & 41.25 & 58.00 \\
\hline & $\mathbf{C M}$ & 10 & 55.43 & 6.18 & 47.00 & 48.00 & 56.00 & 62.00 & 64.00 \\
\hline & MW & 20 & 53.77 & 8.55 & 35.00 & 49.50 & 57.00 & 61.00 & 62.00 \\
\hline
\end{tabular}




\begin{tabular}{|c|c|c|c|c|c|c|c|c|c|}
\hline & TES & 14 & 49.78 & 12.66 & 29.00 & 35.00 & 54.00 & 59.00 & 66.00 \\
\hline \multirow{4}{*}{ 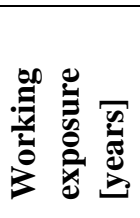 } & CNC & 18 & 8.25 & 4.49 & 2.00 & 5.00 & 8.50 & 10.75 & 19.00 \\
\hline & CM & 10 & 17.71 & 5.88 & 15.00 & 16.00 & 20.00 & 23.00 & 32.00 \\
\hline & MW & 20 & 14.15 & 7.57 & 5.00 & 9.00 & 15.00 & 19.00 & 25.00 \\
\hline & TES & 14 & 11.77 & 4.64 & 5.00 & 7.00 & 12.00 & 15.50 & 19.00 \\
\hline \multirow{4}{*}{ 吾 } & CNC & 18 & 180.25 & 7.93 & 169.00 & 176.00 & 178.00 & 187.00 & 198.00 \\
\hline & $\mathbf{C M}$ & 10 & 179.71 & 6.32 & 167.00 & 176.00 & 181.00 & 183.00 & 189.00 \\
\hline & MW & 20 & 174.77 & 6.28 & 167.00 & 170.00 & 173.00 & 180.00 & 189.00 \\
\hline & TES & 14 & 181,78 & 6.14 & 172.00 & 175.00 & 183.00 & 186.00 & 192.00 \\
\hline \multirow{4}{*}{ 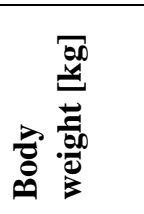 } & $\mathrm{CNC}$ & 18 & 87.83 & 23.27 & 66.00 & 73.00 & 86.50 & 89.75 & 160.00 \\
\hline & $\mathrm{CM}$ & 10 & 84.42 & 16.03 & 70.00 & 71.00 & 82.00 & 90.00 & 120.00 \\
\hline & MW & 20 & 84.92 & 15.27 & 71.00 & 71.00 & 85.00 & 99.50 & 115.00 \\
\hline & TES & 14 & 84.67 & 11.53 & 56.00 & 80.50 & 88.00 & 92.50 & 97.00 \\
\hline \multirow{4}{*}{$\sum_{m e}^{E}$} & CNC & 18 & 26.70 & 4.62 & 21.60 & 24.90 & 25.20 & 27.50 & 40.80 \\
\hline & $\mathrm{CM}$ & 10 & 26.10 & 4.70 & 20.90 & 23.90 & 25.20 & 25.50 & 37.00 \\
\hline & MW & 20 & 27.70 & 4.17 & 21.90 & 24.50 & 27.70 & 30.20 & 31.70 \\
\hline & TES & 14 & 25.58 & 3.11 & 18.30 & 24.31 & 26.60 & 27.76 & 29.70 \\
\hline \multirow{4}{*}{ 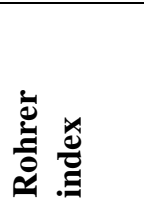 } & CNC & 18 & 1.48 & 0.21 & 1.23 & 1.32 & 1.44 & 1.54 & 2.06 \\
\hline & $\mathrm{CM}$ & 10 & 1.46 & 0.27 & 1.14 & 1.33 & 1.38 & 1.52 & 2.06 \\
\hline & MW & 20 & 1.58 & 0.23 & 1.31 & 1.39 & 1.52 & 1.66 & 2.22 \\
\hline & TES & 14 & 1.41 & 0.18 & 1.04 & 1.31 & 1.42 & 1.51 & 1.73 \\
\hline
\end{tabular}

Table 2. Basic statistical characteristics of somatic data of respondents and selected index's

Table 3 includes results showing the occurrence of difficulties, their location, intensity and musculoskeletal disorders. It shows a visit to the medical doctor in the analysed file due to the occurrence of these problems.

Through these data, it is possible to monitor the effects of work environment factors on employees. The factors of the working environment affect not only the working comfort of employees, but their effect is reflected in the occurrence of difficulties in the musculoskeletal system. The severity of these difficulties is expressed by a visit to the medical doctor.

\begin{tabular}{|c|c|c|c|c|c|c|c|c|c|c|}
\hline \multirow[b]{3}{*}{ MS difficulties } & \multicolumn{10}{|c|}{ Work position } \\
\hline & \multicolumn{2}{|c|}{$\operatorname{CNC}(n=18)$} & \multicolumn{2}{|c|}{$\mathrm{CM}(\mathrm{n}=10)$} & \multicolumn{2}{|c|}{$M W(n=20)$} & \multicolumn{2}{|c|}{ TES $(n=14)$} & \multicolumn{2}{|c|}{ Together } \\
\hline & 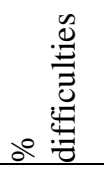 & $\begin{array}{l}\sum_{0}^{0} \cdot \frac{\overrightarrow{0}}{5} \\
0^{\circ}\end{array}$ & o & $\sum_{0}^{A} \cdot \frac{\vec{v}}{>}$ & 象 & 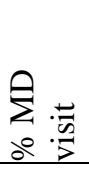 & o & $\sum_{0} \sum_{0} \cdot \frac{\vec{v}}{>}$ & 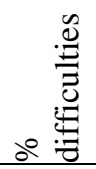 & $\sum_{0} \sum_{0} \cdot \frac{\vec{n}}{>}$ \\
\hline Neck & 4.88 & 0.00 & 4.88 & 2.44 & 14.63 & 2.44 & 4.88 & 0.00 & 29.27 & 4.88 \\
\hline Upper back & 4.88 & 0.00 & 7.32 & 2.44 & 12.19 & 4.88 & 4.88 & 0.00 & 29.27 & 7.32 \\
\hline Lower back, crosses & 14.63 & 4.88 & 14.63 & 9.76 & 14.63 & 9.76 & 9.76 & 4.88 & 53.65 & 29.28 \\
\hline Arms & 2.44 & 2.44 & 7.32 & 4.88 & 17.07 & 2.44 & 0.00 & 0.00 & 26.83 & 9.76 \\
\hline Elbows & 4.88 & 2.44 & 9.76 & 2.44 & 19.51 & 7.32 & 4.88 & 4.88 & 39.03 & 17.08 \\
\hline Wrists, hands & 9.76 & 4.88 & 9.76 & 2.44 & 4.88 & 4.88 & 4.88 & 0.00 & 29.28 & 12.20 \\
\hline Hip joints, thighs & 0.00 & 0.00 & 2.44 & 0.00 & 9.76 & 2.44 & 4.88 & 2.44 & 17.08 & 4.88 \\
\hline Knees & 2.44 & 0.00 & 7.32 & 2.44 & 7.32 & 2.44 & 4.88 & 0.00 & 21.96 & 4.88 \\
\hline Ankles and feet & 0.00 & 0.00 & 4.88 & 2.44 & 7.32 & 4.88 & 4.88 & 2.44 & 17.08 & 9.76 \\
\hline
\end{tabular}

Table 3. Location and intensity of MS difficulties in selected groups of employees 
Work comfort of employees is influenced mainly by factors of work, working environment and mental stress. Respondents rated the load levels of these groups stress factors on a scale of 1 to 10 (minimum, small, medium, high and very heavy load). These are modifiable factors that may affect the occurrence of MS difficulties. Due to the low number of members in the analysed groups, it wasn't possible to count odds ratio values or $95 \%$ confidence limits for all factors that may affect the health of employees. In table 4 shows the average score of the factors of work, which in the monitored groups of employees (according to a subjective evaluation) cause their workload and reduce their working comfort. The medium load is caused by heavy loads handling, long-term work in the same position, insufficient equipment with highquality work tools and unevenly distributed work for respondents working on CNC and conventional machines and for workers performing auxiliary manual work. The group of manual workers identified the lack of high-quality tools as the most important factor which cause their heavy workload. In the group of technical-economic employees (technologists, designers, masters, etc.), the monitored factors create minimal or only a small burden.

\begin{tabular}{|c|c|c|c|c|}
\hline \multirow[t]{2}{*}{ Work factors } & \multicolumn{4}{|c|}{ Work group acronym } \\
\hline & $\mathrm{CNC}$ & CM & MW & TES \\
\hline 1. Performing the same work operations (monotony) & 3.00 & 3.86 & 4.29 & 2.44 \\
\hline 2. Handling heavy, respectively spacious objects & 3.82 & 5.71 & 4.64 & 0.22 \\
\hline 3. Insufficient rest breaks during the work shift & 1.82 & 3.00 & 3.93 & 0.67 \\
\hline 4. Over time, irregular shifts & 0.73 & 2.29 & 1.21 & 1.89 \\
\hline $\begin{array}{l}\text { 5. Work in the same position for a long time (standing, leaning } \\
\text { forward, turning the hull sideways) }\end{array}$ & 4.36 & 5.71 & 4.64 & 2.89 \\
\hline 6. Work with hands over your head or away from the body & 1.36 & 2.14 & 3.14 & 0.22 \\
\hline 7. Working on the border of physical abilities & 0.45 & 4.26 & 4.64 & 0.22 \\
\hline 8. Insufficient equipment with quality tools & 4.73 & 4.57 & 7.5 & 2.11 \\
\hline $\begin{array}{l}\text { 9. Unevenly distributed work (once a lot of work, sometimes } \\
\text { little) }\end{array}$ & 4.18 & 4.71 & 6.36 & 4.00 \\
\hline 10. Other (what kind) & 0.00 & 0.00 & 0.00 & 0.00 \\
\hline
\end{tabular}

Table 4. Influence of labour factors on workload subjectively evaluated by employees

The following table shows the importance of the factors of the working environment on the workload of respondents. These are mainly microclimatic conditions in the workplace and the organization of workplaces. The survey shows that microclimatic conditions are a frequent cause of workplace discomfort. However, these are shortcomings that can be reduced or eliminated by appropriately selected technical measures. Workplace environmental factors such as noise, heat and poor ventilation are the cause of moderate workload for manufacturing employees. Manual workers also stated that the reason for their increased workload is the lack of workplace illumination. The factors monitored by the technical and economic staff cause little or no workload. Some employees working on CNC machines said, in a supplementary option, that discarded tools, which occur in their workplace, are the problem but cause only minimum workload, rather slow them down, when they search necessary tool.

\begin{tabular}{|l|c|c|c|c|}
\hline \multirow{2}{*}{ Work factors } & \multicolumn{4}{|c|}{ Work group acronym } \\
\cline { 2 - 5 } & CNC & CM & MW & TES \\
\hline 1. Noise exposure & $\mathbf{5 . 7 3}$ & $\mathbf{5 . 8 6}$ & $\mathbf{5 . 2 1}$ & 2.11 \\
\hline 2. Vibration exposure & 1.45 & 3.00 & 2.64 & 0.89 \\
\hline 3. Cold load & 1.18 & 1.29 & 3.14 & 1.00 \\
\hline 4. Heat load & $\mathbf{4 . 2 5}$ & $\mathbf{4 . 2 9}$ & $\mathbf{5 . 2 9}$ & 2.22 \\
\hline 5. Insufficient ventilation & $\mathbf{5 . 4 5}$ & $\mathbf{4 . 8 6}$ & $\mathbf{5 . 9 3}$ & 2.67 \\
\hline 6. Insufficient workplace lighting & 3.64 & 3.71 & $\mathbf{5 . 6 4}$ & 0.78 \\
\hline 7. Inappropriate organized workspace & 1.36 & 1.29 & 3.14 & 1.67 \\
\hline 8. Insufficient handling space & 0.91 & 0.86 & 3.57 & 1.33 \\
\hline $\begin{array}{l}\text { 9. Hazards related to the operation of the equipment (eg. related to } \\
\text { cleaning of the machine, contact with cutting fluid, swarfs) }\end{array}$ & 5.45 & 6.00 & 2.36 & 2.00 \\
\hline 10. Other (what kind) & & & & \\
\hline
\end{tabular}

Table 5. Influence of microclimatic factors on workload subjectively evaluated by employees

Psychological stress factors also occurred in the monitored companies. Workers most often marked individual factors as a mean value from the scale, which documents the occurrence of the risk, but not significant. The nature of the factors of mental stress is different according to the way of work of individual working groups, as shown in table 6. It is interesting to note that factors affecting the psychological burden of technical-economic staff affect more than factors of work and working environment, which we assume are related to the nature of their work. These risks can be reduced by introducing training and appropriate personal protective equipment. 


\begin{tabular}{|l|c|c|c|c|}
\hline \multirow{2}{*}{ Mental stress factors } & \multicolumn{3}{|c|}{ Work group acronym } \\
\cline { 2 - 5 } & CNC & CM & MW & TES \\
\hline 1. Working under time pressure & $\mathbf{4 . 0 9}$ & $\mathbf{4 . 8 6}$ & $\mathbf{5 . 5 7}$ & $\mathbf{6 . 1 1}$ \\
\hline 2. The forced pace of work & 2.36 & $\mathbf{4 . 8 6}$ & 3.57 & $\mathbf{4 . 1 1}$ \\
\hline 3. Shift work & 0.91 & 1.57 & 2.57 & 1.11 \\
\hline 4. Concentration-disturbing effects at work & 1.55 & 1.27 & 2.79 & $\mathbf{4 . 7 7}$ \\
\hline 5. Improper communication with employees & 2.45 & 0.91 & $\mathbf{4 . 1 4}$ & 2.27 \\
\hline 6. Inappropriate communication with superiors & 3.00 & 1.82 & 2.50 & $\mathbf{4 . 4 4}$ \\
\hline 7. Workload, fulfilling demanding tasks & 2.82 & 2.91 & 3.64 & $\mathbf{4 . 8 9}$ \\
\hline 8. The risk to your own life and health & $\mathbf{4 . 6 4}$ & 3.36 & 3.93 & 3.00 \\
\hline The risk to life and health of others & 3.00 & $\mathbf{4 . 7 1}$ & 3.43 & 2.00 \\
\hline 10. Other (what kind) & 0.00 & 0.00 & 0.00 & 0.00 \\
\hline
\end{tabular}

Table 6. Influence of factors of psychological stress subjectively evaluated by employees

\section{Discussion}

It will be necessary to take technical measures for this particular sample of respondents to adjust the working plane height, as we have tall men who have indicated lower back pain, rotation and dialling. It indicates that the working plane is low. Directly related to the adjustment, layout of the workplace. Due to the increased age of employees, it is necessary to address the provision of operations with suitable handling means to reduce manual handling, which causes a number of difficulties. From the point of view microclimatic conditions, it is necessary to solve lighting and heat conditions at workplaces, whether by introducing additional lighting or skylights, which in addition to natural lighting also solves the problem of high temperature and insufficient ventilation. If this is not possible, it is advisable to install air conditioning.

To eliminate noise is advisable to eliminate this problem by installing noise barriers, thoroughly servicing technique at workplaces and replacing noisy tools with more suitable ones. It should be introduced to the rotation of employees as an organizational measure. To pay attention to their health and safety training and ergonomics. Equally important is the adaptation of the work and rest regime for employees.

As the results of the pilot survey show, there are factors in the workplace that affect the work performance and comfort of employees. It suggests that it makes sense to address the reduction and elimination of the negative impact of work environment factors. In the sample of respondents selected by us from the analysis of randomly selected companies, it turned out that it is necessary to address the impact of work environment factors on the employee because due to the similar nature of work activities, there are similar shortcomings in workplaces. However, these are factors that can be reduced or eliminated by appropriate technical and organizational measures.

Due to the low sample size in the pilot survey, it is necessary to perform a more detailed analysis in small engineering companies to confirm the impact of selected factors of the work environment in the workplace in order to be able to generalize the results. In addition to the indicated trend of the influence of selected factors of the working environment on employees, it is also necessary to quantify the values of the odds ratio and $95 \%$ confidence limits for all factors that may affect the health of employees. This will be the subject of further research within the project.

The next step will be to gather information on the factors of the working environment in medium and large companies. It is necessary to verify whether the occurrence and intensity of selected factors of the working environment depends on the size of the company or whether the type of industry in which the company operates has a significant impact. Based on a detailed analysis of work environment factors, it will be possible to quantify the impact of selected factors. The results will be used in the creation of the methodology of combination and recombination factors of work comfort of employees, which is the goal of the project VEGA 1/0101/18 - Proposal of the combination and recombination methodology for the work comfort index in mechanical engineering industrial plants.

\section{Conclusion}

Positive and negative factors of the working environment influence employee's behaviour, moods, feelings, his working comfort and are mainly reflected in his work and health. It is important that employers create a suitable working environment for their employees. Efforts to adapt the working environment to employees bring a positive impact not only on the part of employees but also for the company, as they contribute to positive economic results in the form of increasing labour productivity, reducing the number of misfits and better quality of work.

The paper describes the experience and results of the survey in small engineering companies. The survey was used to identify frequently occurring work environment factors affecting the employees' work comfort. The starting point was the analysis of work factors, work environment and workload of the employees, the severity of which is a possible evaluate through the impact on employee's health. It will be necessary to carry out a detailed epidemiological study aimed at evaluating the factors influencing the work comfort of employees in medium and large companies. The results will be included in the proposal of the combination and recombination methodology for the work comfort index in mechanical engineering industrial plants. 


\section{Acknowledgments}

This paper was written with the financial support of the Scientific Grant Agency of the Ministry of Education, Science, Research and Sport of the Slovak Republic and the Slovak Academy of Sciences as a part of the project No. VEGA 1/0101/18 - Proposal of the combination and recombination methodology for the work comfort index in mechanical engineering industrial plants.

\section{References}

[1] Aleksić, A. et al. (2009) Bezbednost i zdravlje na radu. Monograph. Novi Sad, Serbia.

[2] Cadieux, J., Roy, M. and Desmarais, L. (2006) 'A preliminary validation of a new measure of occupational health and safety', Journal of Safety Research, 37(4), pp. 413-419. doi: 10.1016/j.jsr.2006.04.008

[3] https://articles.bplans.com/creating-positive-work-environment/, (2020). Creating a Positive Work Environment, Accessed on: 2020-09-10

[4] https://www.eurofound.europa.eu/sk/surveys, (2019). European Working Conditions Survey, Accessed on: 201911-02

[5] DeJoy, D.M., Schaffer, B.S., Wilson, M.G., Vandenberg, R.J., Butts, M.M., 2004. Creating safer workplaces: assessing the determinants and role of safety climate. Journal of Safety Research 35, 81-90.

[6] Fernández-Muñiz, B., Montes-Peón, J.M., Vázquez-Ordás, C.J., 2007. Safety Culture: analysis of the causal relationships between its key dimensions. Journal ofSafety Research 38, 627-641.

[7] Fernández-Muñiz, B., Montes-Peón, J. M. and Vázquez- Ordás, C. J. (2009) 'Relation between occupational safety management and firm performance', Safety Science. Elsevier Ltd, 47(7), pp. 980-991. doi: 10.1016/j.ssci.2008.10.022.

[8] https://www.istp.sk/clanok/35/pracovne-prostredie, (2019). Internet labor market guide. Work environment, Accessed on: 2019-11-02

[9] Kapustová, M., (2004). Application of mathematical methods in ecological work environment in engineering operations, Available from: https://www.mtf.stuba.sk/buxus/docs/internetovy_casopis/2004/2/kapustova.pdf, Accessed: 2019-11-02

[10] Markova, P., Prajova, V., Homokyova, M. \& Horvathova, M. (2019). Human Factor in Industry 4.0 in Point of View Ergonomics in Slovak Republic, Proceedings of the 30th DAAAM International Symposium, pp.0284-0289, B. Katalinic (Ed.), Published by DAAAM International, ISBN 978-3-902734-22-8, ISSN 1726-9679, Vienna, Austria DOI: 10.2507/30th.daaam.proceedings.037

[11] Paulíková, A., Ubárová, M. 2018. Proposal of indexing process of working comfort factors in operations. In: VIII. medzinárodná vedecká konferencia, Bratislava, 9. november 2018, ISBN 978-80-89753-24-6

[12] Rundmo, T., Hale, A., 2003. Managers' attitudes towards safety and accident prevention. Safety Science 41, 557574.

[13] Vulanovic, S., Zizakov, M., Vasic, S., Delic, M. \& Sremcev, N. (2019). The Impact of Occupational Health and Safety (OH\&S) Management Systems on Risk Management Practices, Proceedings of the 30th DAAAM International Symposium, pp.1188-1195, B. Katalinic (Ed.), Published by DAAAM International, ISBN 978-3902734-22-8, ISSN 1726-9679, Vienna, Austria DOI: 10.2507/30th.daaam.proceedings.167

[14] Vulanović, S., Delić, M., Ćosić, I., Žižakov, M., \& Vasić, S. (1848). Influence of occupational stress on organisanalzational performance, Technical Gazette, 2019, ISS 1330-3651, DOI: 10.17559/TV-20190602145208.

[15] http://www.ilo.ch/global/topics/working-conditions/lang--en/index.htm, (2020). Working conditions, Accessed on: 2020-09-10 